\title{
As políticas de expansão do Ensino Superior no Brasil e a formação em cinema e audiovisual
}

\author{
Expansion policies for Higher Education in Brazil and professional qualification in \\ cinema and audiovisual
}

\author{
Ricardo Normanha \\ Doutor em Ciências Sociais \\ Grupo de Pesquisa em Diferenciação Sociocultural - FE/Unicamp \\ Professor Substituto do IFSP - Campus Pirituba \\ São Paulo, SP - Brasil \\ normanha.ricardo@gmail.com
}

Resumo: $\mathrm{O}$ artigo teve como objetivo central observar as complexidades da formação profissional em cinema e audiovisual, em nível superior no Brasil. Assim sendo, atentou-se para as transformações nas políticas públicas educacionais, ocorridas nas últimas décadas, tomando como recorte empírico o período de 1995 a 2016. Observou-se que, embora o crescimento significativo no número de cursos e matriculados em instituições públicas, notadamente, nas Universidades Federais, seja de grande importância, as instituições privadas de ensino ainda assumem posição central na formação de profissionais do cinema e do audiovisual. Articulada a essa observação, notou-se também a centralidade que as exigências do dinâmico mercado de trabalho, no campo do cinema e do audiovisual, ocupam na estruturação dos cursos de nível superior.

Palavras-chave: ensino superior; cinema; audiovisual; mercado de trabalho; políticas públicas para o ensino superior.

Abstract: The main objective of this paper is to present the current framework of university education and professional education in cinema and audiovisual in Brazil, focusing on recent changes in educational public policies in recent decades, taking the period from 1995 to 2016 as empirical perspective. It is observed that although the significant growth in the number of courses and enrolled students in public institutions, notably in federal universities, is of great importance, private educational institutions still assume a central position in the training of cinema and audiovisual professionals. Linked to this observation, we also notice the centrality that the demands of the dynamic labor market in the cinema and audiovisual area occupy in the structuring of university education courses.

Key-words: university education; cinema; audiovisual; labor market; public policy in university education.

Cite como

(ABNT NBR 6023:2018)

NORMANHA, Ricardo. As políticas de expansão do Ensino Superior no Brasil e a formação em cinema e audiovisual. Dialogia, São Paulo, n. 38, p. 1-18, e19326, maio/ago. 2021. Disponível em: https://doi.org/10.5585/dialogia.n38.19326.

American Psychological Association (APA)

Normanha, R. (2021, maio/ago.). As políticas de expansão do Ensino Superior no Brasil e a formação em cinema e audiovisual. Dialogia, São Paulo, 38, p. 1-18, e19326. https://doi.org/10.5585/dialogia.n38.19326. 


\section{Introdução}

O crescimento das atividades relacionadas ao audiovisual no Brasil, sobretudo a partir de meados dos anos de 1990, tem demandado uma quantidade cada vez maior de profissionais no mercado de trabalho. O cinema, em especial, tem experimentado uma larga expansão de mercado, se considerarmos o aumento no número de títulos lançados por ano, conforme dados que serão apresentados mais adiante. Em consonância com esta demanda de profissionais, as instituições de ensino, sejam elas de ensino superior, técnico, ou ainda, os cursos livres, se mostraram dispostas a oferecer as ferramentas para a formação destes profissionais. Além disso, podem-se associar ao fenômeno da universalização da produção e consumo de materiais audiovisuais, a dinâmica social atrelada ao ciclo de crescimento econômico e a consequente política de transferência de renda ainda que bastante limitada e muito pouco transformadora - colocada em prática pelos governos do Partido dos Trabalhadores. Dessa associação, deriva-se também o crescimento das universidades (públicas e privadas) e o ingresso de jovens mais pobres no ensino superior.

Faz parte do senso comum associar as atividades artísticas às atribuições de ordem quase metafísica como "dom" e inspiração e, por sua natureza subjetiva, a arte é constantemente relacionada a estas habilidades, que, muitas vezes, podem ser inatas ou desenvolvidas de forma muito própria nos indivíduos que se destacam no universo artístico. No entanto, há que se ressaltar que, cada vez mais, sobretudo em alguns campos artísticos que requerem certo aparato técnico e tecnológico, há a necessidade, por parte dos artistas, do domínio de um número crescente de habilidades e conhecimentos específicos para a realização de suas atividades.

No cinema, há algumas décadas, a grande maioria dos profissionais, especialmente nas funções de criação, era autodidata e isso se devia a uma confluência de fatores. Em primeiro lugar, porque até um passado recente, o número de escolas de formação em cinema era bastante reduzido. Há também que se destacar que o cinema é uma forma de expressão artística mais jovem do que a literatura e as artes plásticas, por exemplo. Nesse sentido, pode-se compreender que há 30 ou 40 anos, o cinema ainda era uma arte em formação, em desenvolvimento, o que, em certa medida, contribuiu para a ausência de um ensino formalizado desta arte. Se for pensar na realidade brasileira, deve-se dar relevância para a produção muito pouco expressiva de filmes, de modo que o número de profissionais envolvidos não justificaria a consolidação de escolas de cinema no país. No entanto, tendo em vista a complexidade da produção cinematográfica e audiovisual na atualidade, bem como o incremento tecnológico pelo qual essa atividade passa constantemente, associado ao número cada vez maior de produções e de profissionais envolvidos, não podemos pensar mais no cinema como algo exclusivamente realizado por profissionais formados pela prática, imbuídos de 
grande inspiração artística. E, embora o autodidatismo ainda esteja presente na prática cinematográfica, cada vez mais o cinema requer profissionais especializados e que, além da experiência que só a prática é capaz de oferecer, tenham conhecimentos sólidos de seus campos de atuação.

O cineasta e professor Nelson Pereira dos Santos, fundador do Curso de Cinema de Brasília e da Universidade Federal Fluminense, pensa o ensino de cinema muito mais como laboratório de práticas do que propriamente como um curso estruturado sobre bases de ensino rígidas e predeterminadas (MARQUES; AMÂNCIO, 2014).

Mesmo pensando na complexidade do cinema na atualidade, cuja técnica ocupa um espaço primordial, Nelson Pereira dos Santos reforça a importância do espaço criativo na formação profissional dos cineastas brasileiros.

\begin{abstract}
O que é uma escola de cinema? Ela tem o seu momento técnico. E isso é pão-pão, queijoqueijo. Elementar. Agora, tem o outro lado, que é a criação. E a melhor forma de fazer com que os alunos exercitem a criação é mantê-los em liberdade. Por exemplo, eu acho que só se devia falar de história do cinema, teoria de cinema, no final do curso. A primeira coisa é dar toda a liberdade para fazer [...] Aprender a usar, inventar e realizar o que inventou. Depois que vai discutir o realismo, surrealismo etc. Não ficar prisioneiro. De repente, fica muito fechado. Eu não sabia que tinha que ser assim. Eu fui fazendo assim, porque eu me formei de uma forma muito livre (MARQUES; AMÂNCIO, 2014, p. 23).
\end{abstract}

Nesse sentido, o que está presente nas colocações de Nelson Pereira dos Santos é que, mesmo nos cursos formais de cinema, o aprendizado se dá na prática, na experiência concreta da realização do filme e na conformação de equipes de trabalho nas quais os conhecimentos sobre os processos de trabalho são transmitidos pelos profissionais mais experientes aos novatos. É o que Bulloni (2016) observa no mercado de trabalho de vídeos publicitários.

Observamos assim que, num contexto de alta mobilidade (inserções transitórias e em empresas diversas), os grupos de trabalho formados em torno dos diversos ofícios ou especializações desempenham de fato um papel muito importante na aquisição e na transmissão de conhecimentos e práticas relativas ao exercício do trabalho no setor (BULLONI, 2016, p. 48).

Residem exatamente nesta justa medida entre teoria e prática os grandes desafios para a formação de profissionais do cinema e do audiovisual no Brasil hoje. De acordo com Ribeiro, et al. (2017), a partir do que se convencionou chamar de "pós-retomada" do cinema brasileiro, a preocupação com a formação profissional e sua sintonia com o mercado de cinema e audiovisual se tornou ponto de pauta imprescindível no pensamento cinematográfico brasileiro. Nesse sentido, o III Congresso Brasileiro de Cinema, realizado em 2000, deu o pontapé inicial para a institucionalização de uma instância para se pensar e discutir a formação profissional. A partir da deliberação do Congresso, em 2001 surge o Fórum Brasileiro de Ensino de Cinema e Audiovisual 
(Forcine), entidade responsável pela "interlocução das escolas de cinema e audiovisual com o mercado" (RIBEIRO et al., 2017, p. 77).

\section{A formação profissional em nível superior}

Os cursos de ensino superior pioneiros foram criados ao longo da década de 1960. Embora o anseio pela criação de escolas superiores de cinema viesse de várias partes do meio cinematográfico, é da Igreja Católica que surgem os primeiros cursos universitários de cinema. Em 1962, vê-se o surgimento da Escola Superior de Cinema da Universidade Católica de Minas Gerais e da Escola Superior de Cinema São Luiz, em São Paulo (RIBEIRO, et al., 2017; RODRIGUES, 2014) ${ }^{1}$. Em 1965, surge o curso de Cinema da Universidade de Brasíliaª ${ }^{2}$ A Universidade de São Paulo cria o curso de Cinema (mais tarde transformado em Audiovisual), em 1966. A Universidade Federal Fluminense, por sua vez, inaugura o curso de Cinema, em 1967, e a Fundação Armando Álvares Penteado, em 1972 (RIBEIRO et al., 2017; RODRIGUES, 2014; MOURÃO, 2014). Todos eles, de acordo com Mourão (2014), eram cursos caracterizados pela flexibilidade acadêmica, prezando pela formação ampla.

“O objetivo principal era a formação de diretores, objetivo este em total consonância com a ideologia dominante do 'cinema de autor', além de enfatizar a necessidade de realizar filmes que refletissem sobre nossa realidade social” (MOURÃO, 2014, p. 25). Até hoje, esses cursos estão entre os mais tradicionais e reconhecidos no país. O hiato que se percebe entre a criação destes cursos nos anos 1960 e as mudanças no cenário da formação profissional nos anos de 1990 confirma a ideia de que o empirismo, ou seja, o aprendizado pela prática, é uma característica fundamental do cinema nacional. "O empirismo não só era uma realidade como era, de certa forma, celebrado como original e como algo bem brasileiro" (RIBEIRO et al., 2017, p. 77).

Mas as mudanças técnicas e tecnológicas, sobretudo o advento e a popularização do vídeo digital e a retomada do cinema brasileiro em meados dos anos de 1990, trouxeram à tona também a necessidade de reformulação dos parâmetros de formação profissional. "[...] é a partir dos anos 1995 que a linguagem audiovisual, o modelo de produção, a preservação, a difusão, a exibição e o

\footnotetext{
${ }^{1}$ Rodrigues (2014) explicita a intenção da Igreja Católica ao criar os cursos de cinema: "Das encíclicas do Vaticano, duas chamam particular atenção pelo enfoque no cinema: a Vigilanti Cura, do Papa Pio X (1936) e a do Papa Pio XII, chamada Miranda Prorsus, "Sobre a Cinematografia, o Rádio e a Televisão" (1957). Pregava a Vigilanti Cura que o cinema, como um poderoso meio de divulgação, precisava se colocar a serviço do aperfeiçoamento humano, sendo de grande utilidade na transmissão da educação e instrução, desde que se livrasse da influência dos maus instintos e do lucro. Conclamava a todos a só produzirem e divulgarem filmes que não rebaixassem o senso moral dos espectadores. Preocupava-se, ainda, com o fato do espaço coletivo do cinema, reunindo grupos em uma sala escura, levasse a um "entusiasmo depravado", com a sedução exercida pelos atores e atrizes, lotados de atributos físicos, sobre crianças e adolescentes".

${ }^{2}$ Este curso, com a intervenção do regime civil-militar ainda na década de 1960 , esvaziou-se com a demissão de grande parte do corpo docente - ou por decisão do reitor-interventor ou por solidariedade aos perseguidos pelo regime - deixando de existir por alguns anos.
} 
ensino da atividade audiovisual têm experimentado transformações mais evidentes, advindas das rápidas mudanças do paradigma tecnológico” (MOURÃO, 2014, pp. 25 - 26).

Ao observarmos, em série histórica, a evolução do número de cursos de graduação oferecidos no País, já devemos ter em conta um fator fundamental. A nomenclatura adotada pelos cursos e pela própria prática profissional do cinema acompanha as profundas transformações dos paradigmas tecnológicos, uma vez que "muitos dos termos e conceitos aplicáveis ao cinema e à televisão anteriores à era digital não são aplicáveis a nova realidade” (MOURÃO, 2014, p. 27). A própria nomenclatura Audiovisual já infere o processo de convergência de mídias, tecnologias e suportes no qual o cinema está inscrito. Nesse sentido, é preciso pensar no cinema como parte integrante de um universo agora denominado Audiovisual, que, em muitos aspectos, não apresenta limites claros e bem definidos entre os seus diversos campos. Assim, para se observar os cursos de formação de profissionais para o cinema, é necessário ter em conta que eles podem ter sua formação em cursos mais amplos que envolvem os diversos campos do Audiovisual.

A seguir, apresentam-se alguns dados referentes à expansão do ensino superior em cinema e audiovisual com base nas informações disponibilizadas pelo Instituto Nacional de Estudos e Pesquisas Educacionais Anísio Teixeira do Ministério da Educação (INEP - MEC), que desde 1995 realiza o Censo da Educação Superior. Para tanto, optou-se por selecionar alguns anos-chave para a compreensão tanto das políticas de expansão do ensino superior, quanto para a estruturação da produção audiovisual e cinematográfica brasileira. Já de início, o primeiro censo realizado pelo INEP-MEC coincide com o ano que marca a retomada do cinema brasileiro e com o início do primeiro mandato de Fernando Henrique Cardoso à frente do governo federal. No entanto, conforme será argumentado a seguir, os dados referentes ao censo de 1995 são muito pouco precisos e explicativos para o propósito deste trabalho.

Dessa forma, o ano de 2000 foi escolhido para que se possa ter uma breve noção do delineamento das políticas de expansão do ensino superior, levadas a cabo pelos mandatos de Fernando Henrique Cardoso, além de evidenciar as novas metodologias de apresentação dos dados do Censo da Educação Superior. Em seguida, o ano de 2003 foi selecionado com o intuito de apresentar o cenário do ensino superior no Brasil, quando Luiz Inácio Lula da Silva assume a Presidência da República e dá início a um processo de inflexão neodesenvolvimentista nas políticas públicas, conforme também será analisado mais adiante. Esse também é o ano em que o cinema brasileiro entra no que a literatura convencionou denominar de "pós-retomada", marcado, entre outras coisas, pela entrada e consolidação de uma grande empresa de mídia no mercado cinematográfico, qual seja, a Globo Filmes. 
Em 2010 o país vive o auge do projeto petista de crescimento econômico e desenvolvimento social. Nesse ano é possível observar os resultados da política de expansão do ensino superior que, embora tenham mantido a prevalência do setor privado, beneficiou em larga medida a ampliação das universidades federais. Por fim, apresentam-se os dados do Censo da Educação Superior de 2016, marco final da era petista no governo federal e o ano um do regime que se instalou no comando do país por meio de um processo que abreviou não só o mandato da presidenta Dilma Rousseff, como também interrompeu o regime político em voga desde a promulgação da Constituição de 1988.

\subsection{A era neoliberal}

Assim, ao observarmos os dados da Sinopse Estatística dos Censos do Ensino Superior entre 1995 e 1998, não se encontram Cursos de Graduação Presenciais com nomenclaturas específicas, como Cinema ou Audiovisual. No entanto, podemos perceber a existência de outros cursos cuja formação pode oferecer habilitações para o trabalho no cinema, como é o caso de Artes Visuais, Belas Artes e Comunicação Social. A ausência de informações detalhadas e o agrupamento dos cursos em áreas gerais dificultam a compreensão do real cenário da formação em cinema e audiovisual entre o primeiro Censo, em 1995, e o Censo de 2000, quando já é possível observar uma classificação mais elaborada e detalhada dos cursos.

Dessa forma, tinha-se, em 1995, 135 cursos $^{3}$ voltados para a formação em comunicação e artes, a maior parte deles, 81 - 60\% do total - em instituições privadas de ensino superior. Entre as instituições públicas, as federais eram as que mais ofertavam esses cursos, com $61 \%$ do total. Em relação ao número de matriculados, as instituições privadas congregavam mais de $75 \%$ dos alunos e as federais eram as instituições com a maior fatia dos alunos matriculados entre as instituições públicas, em 1995.

Entre os anos de 1996 e 1998, os dados do Censo da Educação Superior não apresentaram grandes alterações nesse cenário, embora em 1998 pôde se destacar o registro do curso de graduação sequencial em Fotografia, em uma instituição privada de ensino e que, segundo o Censo da Educação Superior, apresentou apenas dois alunos matriculados. Em 1999, houve, pela primeira vez, o registro de um curso com o nome Cinema, oferecido por uma instituição privada, com 244 alunos matriculados.

\footnotetext{
${ }^{3}$ Estão sendo considerados aqui os cursos de Comunicação Social, Comunicação Visual, Artes Visuais e Belas Artes. O curso de Comunicação Social é o que mais contribui para este número total de cursos. No entanto, por se tratar de um curso de grande abrangência e de múltiplas possibilidades de habilitações específicas (Relações Públicas, Jornalismo, Produção Editorial, Rádio e TV, Publicidade e Propaganda), tornase difícil tratá-lo especificamente como um curso voltado à formação de profissionais de cinema e audiovisual.
} 
No Censo da Educação Superior de 2000, o cenário dos cursos de graduação, voltados para a formação em Comunicação e Artes e que podiam oferecer habilitações para o trabalho em cinema, tornou-se mais complexo. Nesse ano, além do retorno do curso de Comunicação Visual, ocorreu o surgimento dos cursos Arte e Mídia, Cinema e Animação, Artes Gráficas, Audiovisuais, Multimídia, Produção de Multimídia e Cinema e Vídeo. Vale notar que, no Censo de 2000, esses cursos estavam agrupados em áreas gerais e áreas detalhadas. Aponta-se para a peculiaridade do curso de Cinema e Vídeo estar relacionado à área de Jornalismo e Reportagem, enquanto os demais cursos mencionados estavam classificados nas áreas de Artes, Belas Artes e Técnicas Audiovisuais e Produção de Mídia. Os cursos de Comunicação Social não foram considerados nesta análise, uma vez que, a partir do Censo de 2000, os dados já estavam especificados em relação às habilitações. Consideram-se somente as habilitações específicas nas áreas de cinema, audiovisual e mídia. Sendo 20 cursos de graduação, dos quais 11 estavam nas instituições privadas e nove nas instituições públicas. Entre as públicas, as federais eram as que mais ofereciam essas formações. As tabelas a seguir mostram a distribuição desses cursos e do número de matriculados no que tange ao tipo de instituição de ensino superior.

Tabela 1 - Número de cursos de graduação presenciais relacionados à formação em cinema e audiovisual no Brasil em 2000.

\begin{tabular}{llllll}
\hline Número de Cursos de Graduação Presenciais - 2000 & & & \\
\hline Curso & Total & Pública & & & Privada \\
& & Federal & Estadual & Municipal & Privada \\
\hline Artes e Mídia & 2 & 1 & - & - & 1 \\
Artes Visuais & 7 & 3 & - & - & 4 \\
Belas Artes & 1 & 1 & - & - & - \\
Cinema e Animação & 2 & - & - & - & 2 \\
Artes Gráficas & 2 & 1 & - & - & 1 \\
Audiovisuais & 1 & - & 1 & - & - \\
Comunicação Visual & 1 & 1 & - & - & - \\
Fotografia & 1 & - & - & - & 1 \\
Multimídia & 1 & - & - & - & 1 \\
Produção de Multimídia & 1 & - & - & - & 1 \\
Cinema e Vídeo & 1 & - & 1 & - & - \\
\hline Total & 20 & 7 & 2 & - & 11 \\
\hline
\end{tabular}

Fonte: INEP - MEC. Dados do Censo da Educação Superior, 2000. Elaboração própria. 
Tabela 2 - Número de matriculados nos cursos de graduação presenciais relacionados à formação em cinema e audiovisual no Brasil em 2000

\begin{tabular}{llllll}
\hline Matriculados nos Cursos de Graduação Presenciais - 2000 & & \\
\hline Cursos & Total & $\begin{array}{l}\text { Pública } \\
\text { Federal }\end{array}$ & Estadual & Municipal & Privada \\
\hline Artes e Mídia & 151 & 31 & - & - & 120 \\
Artes Gráficas & 236 & 102 & - & - & 134 \\
Artes Visuais & 1339 & 796 & - & - & 543 \\
Audiovisuais & 35 & - & 35 & - & - \\
Belas Artes & 322 & 322 & - & - & - \\
Cinema e Animação & 348 & - & - & - & 348 \\
Cinema e Vídeo & 56 & - & 56 & - & - \\
Comunicação Visual & 89 & 89 & - & - & - \\
Fotografia & 78 & - & - & - & 78 \\
Multimídia & 108 & - & - & - & 108 \\
Produção de Multimídia & 90 & - & - & - & 90 \\
\hline Total & $\mathbf{2 8 5 2}$ & $\mathbf{1 3 4 0}$ & $\mathbf{9 1}$ & $\mathbf{0}$ & $\mathbf{1 4 2 1}$ \\
\hline
\end{tabular}

Fonte: INEP - MEC. Dados do Censo da Educação Superior, 2000. Elaboração própria.

Em 2000, entre os matriculados temos 1544 mulheres e 1308 homens, ou 54,1\% de mulheres e 45,9\% de homens. Ainda em relação ao número de matriculados, o que se nota é um equilíbrio entre as instituições públicas $(50,1 \%)$ e privadas $(49,9 \%)$, sendo que as públicas ainda possuem uma ligeira vantagem. Mais uma vez, são as federais que concentram a maior parte dos alunos das instituições públicas, com 93,6\%.

\subsection{Expansão do Ensino Superior Federal e Privado nos governos petistas}

Em 2003, primeiro ano da sequência de governos do Partido dos Trabalhadores no âmbito Federal, já se observava um cenário de incremento no que tange à variedade e ao número de cursos relacionados à formação de profissionais de cinema e audiovisual. Notava-se que, já em 2003, o setor privado era aquele que mais oferecia cursos na área e que possuia o maior número de matriculados. Em termos percentuais, as instituições privadas de ensino ofereceram $76,2 \%$ dos cursos e congregaram 58,9\% dos alunos matriculados, em 2003. Entre as instituições públicas, as federais permaneceram como as que mais concentraram cursos e matriculados, representando, respectivamente, $71,4 \%$ e $85,2 \%$, conforme apontam as tabelas a seguir: 
Tabela 3 - Número de cursos de graduação presenciais relacionados à formação em cinema e audiovisual no Brasil em 2003

\begin{tabular}{|c|c|c|c|c|c|}
\hline \multicolumn{6}{|c|}{ Número de Cursos de Graduação Presenciais - 2003} \\
\hline \multirow{2}{*}{ Curso } & \multirow{2}{*}{ Total } & \multicolumn{3}{|l|}{ Pública } & \multirow{2}{*}{$\begin{array}{l}\text { Privada } \\
\text { Privada }\end{array}$} \\
\hline & & Federal & Estadual & Municipal & \\
\hline Artes e Mídia & 3 & 1 & - & - & 2 \\
\hline Artes Visuais & 19 & 5 & 1 & 1 & 12 \\
\hline Belas Artes & 2 & 1 & - & - & 1 \\
\hline Cinema e Animação & 4 & - & - & - & 4 \\
\hline Artes Gráficas & 2 & 1 & - & - & 1 \\
\hline Audiovisuais & 1 & - & 1 & - & - \\
\hline Comunicação Visual & 3 & 1 & - & - & 2 \\
\hline Criação Gráfica & 13 & - & - & - & 13 \\
\hline Edição de Filme e Vídeo Tape & 1 & - & - & - & 1 \\
\hline Fotografia & 3 & - & - & - & 3 \\
\hline Iluminação & 1 & - & - & - & 1 \\
\hline Multimídia & 2 & - & - & - & 2 \\
\hline Produção Cinematográfica & 1 & - & - & - & 1 \\
\hline Produção de Multimídia & 2 & - & - & - & 2 \\
\hline Som e Imagem & 1 & 1 & - & - & - \\
\hline Cinema e Vídeo & 1 & - & 1 & - & - \\
\hline Total & 59 & 10 & 3 & 1 & 45 \\
\hline
\end{tabular}

Fonte: INEP - MEC. Dados do Censo da Educação Superior, 2003. Elaboração própria. 
Tabela 4 - Número de matriculados nos cursos de graduação presenciais relacionados à formação em cinema e audiovisual no Brasil em 2003

\begin{tabular}{llllll}
\hline Matriculados nos Cursos de Graduação Presenciais - 2003 & & \\
\hline Cursos & Total & Pública & & & Privada \\
& & Federal & Estadual & Municipal Privada \\
\hline Artes e Mídia & 257 & 100 & - & - & 157 \\
Artes Visuais & 2508 & 945 & 20 & 204 & 1339 \\
Belas Artes & 314 & 314 & - & - & - \\
Cinema e Animação & 756 & - & - & - & 756 \\
Artes Gráficas & 551 & 289 & - & - & 262 \\
Audiovisuais & 137 & - & 137 & - & - \\
Comunicação Visual & 265 & 247 & - & - & 18 \\
Criação Gráfica & 314 & - & - & - & 314 \\
Edição de Filme e Vídeo Tape & 12 & - & - & - & 12 \\
Fotografia & 308 & - & - & - & 308 \\
Iluminação & - & - & - & - & - \\
Multimídia & 31 & - & - & - & 31 \\
Produção Cinematográfica & 39 & - & - & - & 39 \\
Produção de Multimídia & 281 & - & - & - & 281 \\
Som e Imagem & 189 & 189 & - & - & - \\
Cinema e Vídeo & - & - & - & - & $\mathbf{3 5 1 7}$ \\
\hline Total & $\mathbf{5 9 6 2}$ & $\mathbf{2 0 8 4}$ & $\mathbf{1 5 7}$ & $\mathbf{2 0 4}$ & \\
\hline Font & & & - & - & - \\
\hline
\end{tabular}

Fonte: INEP - MEC. Dados do Censo da Educação Superior, 2003. Elaboração própria.

Em 2003, a proporção entre mulheres e homens no que tange ao número total de matriculados era de 53,2\% de mulheres e 46,8\% de homens. Em números absolutos, havia 3173 mulheres e 2789 homens.

Entre 2000 e 2003 o que se percebeu foi um crescimento de 195\% no número de cursos e de 109\% no de matriculados. Essa elevação foi maior entre as instituições privadas que, em número de cursos, aumentaram 309\%, enquanto as públicas cresceram 55,5\%. Quando se observou o número de matriculados, percebeu-se que o setor privado apresentava um incremento de 147,5\% e o setor público de apenas $70,8 \%$. O equilíbrio em número de matriculados nas instituições públicas e privadas apresentado em 2000 sucumbiu à primazia do setor privado em 2003, que concentrou quase $59 \%$ dos matriculados nos cursos selecionados. Nesse sentido, vale enfatizar a 
agenda de ajustes neoliberais colocadas em prática pelos oito anos de governo de Fernando Henrique Cardoso. Em consonância com os preceitos ditados pelo Banco Mundial e pelo Fundo Monetário Internacional, as políticas educacionais adotadas no período visavam à redução do papel do Estado no setor, congelando novos investimentos e deixando para o setor privado a incumbência da formação profissional, inclusive aquela realizada no ensino superior. Nas recomendações dos documentos produzidos pelo Banco Mundial, no que tange à educação superior, é nítida a intenção privatista do ensino superior em países em desenvolvimento, como o Brasil (DOURADO, 2002).

Nesse sentido, a LDB impôs ao ensino superior alterações que implicaram em um processo de descentralização e flexibilização, minimizando o papel do Estado na promoção desse nível de ensino, ao mesmo tempo em que promoveu instrumentos de controle e padronização por meio dos processos avaliativos. Associada às determinações da LDB, o Plano Nacional de Educação indicou diretrizes claras para o ensino superior no sentido de ampliar esse nível de ensino sem que essa política demandasse uma ampliação dos recursos vinculados ao governo federal.

Embora a marca dos dois mandatos de Fernando Henrique Cardoso tenha sido a reforma do Estado e a aplicação da agenda de ajustes neoliberais, o cenário que se desenhou a partir da posse de Luiz Inácio Lula da Silva na presidência da República não foi de ruptura, de inversão ou de correção de curso. Pelo contrário, a chegada do PT ao governo federal foi marcada por uma inflexão conservadora das frações dominantes dentro do partido, que constituiu suas bases nos movimentos sociais, porém engendrou uma política de alianças com diferentes setores das classes dominantes brasileiras e do capital nacional e internacional.

Conforme apontaram os dados do Censo da Educação Superior dos anos subsequentes à chegada do PT ao governo federal, o setor privado permaneceu como o principal formador de profissionais para o campo do cinema e do audiovisual. No início da década de 2010, o país vivia o auge da política neodesenvolvimentista, colocada em prática nos dois mandatos de Lula na presidência, cenário que possibilitou a eleição de Dilma Rousseff para assumir o terceiro mandato consecutivo do Partido dos Trabalhadores no comando do governo federal, em meio a um clima de crescimento econômico alavancado pelo alto preço das commodities no mercado externo, pela descoberta do pré-sal e pela inacreditável sensação de que a crise econômica que assolava o mundo capitalista desde 2008 não chegaria ao país.

Em relação a 2003, o Censo da Educação Superior de 2010 indicou um crescimento da ordem de 169,5\% do número de cursos de graduação presencial que formaram profissionais de cinema e audiovisual. Entre o número de matriculados, esse aumento foi de 157,6\%. No período, 
as instituições privadas tiveram crescimento de quase 137,8\% do número de cursos, e de 191,5\% do número de matrículas. Entre as instituições públicas, o crescimento foi da ordem de $271,4 \%$ do número de cursos e de 108,8\% do número de matrículas. As federais foram as que apresentaram um significativo aumento de $290 \%$ do número de cursos e de $87,7 \%$ do número de matriculados no período de 2003 a 2010.

Foi possível notar ainda que as instituições federais permaneceram apresentando o maior número de cursos e matriculados entre as instituições públicas em 2010, representando 75\% dos cursos oferecidos e $76,5 \%$ dos matriculados. O setor privado, por sua vez, representou $67,3 \%$ do total de cursos e $65,3 \%$ dos matriculados na área, no ano, conforme pode ser observado nas tabelas a seguir:

Tabela 5 - Número de cursos de graduação presenciais relacionados à formação em cinema e audiovisual no Brasil em 2010.

\begin{tabular}{lccccc}
\hline Número de Cursos de Graduação Presenciais - 2010 & & & \\
\hline Curso & Total & Pública & & & Privada \\
& & Federal & Estadual & Municipal & Privada \\
\hline Artes e Mídia & 1 & 1 & - & - & - \\
Artes Visuais & 44 & 22 & 8 & 1 & 13 \\
Belas Artes & 2 & - & - & - & 2 \\
Cinema e Animação & 2 & 2 & - & - & - \\
Cenografia & 5 & 1 & - & - & 4 \\
Artes Gráficas & 1 & 1 & - & - & - \\
Audiovisuais & 34 & - & 1 & 1 & 32 \\
Fotografia & 19 & - & - & - & 19 \\
Multimídia & 2 & 1 & - & - & 1 \\
Produção de Multimídia & 27 & 2 & - & - & 25 \\
Som e Imagem & 1 & 1 & - & - & - \\
Cinema e Vídeo & 21 & 8 & 2 & - & 11 \\
\hline Total & $\mathbf{1 5 9}$ & $\mathbf{3 9}$ & $\mathbf{1 1}$ & $\mathbf{2}$ & $\mathbf{1 0 7}$ \\
\hline
\end{tabular}

Fonte: INEP - MEC. Dados do Censo da Educação Superior, 2010. Elaboração própria. 
Tabela 6 - Número de matriculados nos cursos de graduação presenciais relacionados à formação em cinema e audiovisual no Brasil em 2010

\begin{tabular}{|c|c|c|c|c|c|}
\hline \multicolumn{6}{|c|}{ Matriculados nos Cursos de Graduação Presenciais - 2010} \\
\hline \multirow{2}{*}{ Cursos } & \multirow{2}{*}{ Total } & \multicolumn{3}{|l|}{ Pública } & \multirow{2}{*}{$\begin{array}{l}\text { Privada } \\
\text { Privada }\end{array}$} \\
\hline & & Federal & Estadual & Municipal & \\
\hline Artes e Mídia & 119 & 119 & - & - & - \\
\hline Artes Visuais & 4256 & 2230 & 649 & 18 & 1.359 \\
\hline Belas Artes & 64 & . & . & . & 64 \\
\hline Cinema e Animação & 189 & 189 & . & . & . \\
\hline Cenografia & 168 & 65 & . & . & 103 \\
\hline Artes Gráficas & 143 & 143 & . & . & . \\
\hline Audiovisuais & 3.186 & . & 201 & 27 & 2.958 \\
\hline Fotografia & 1.776 & . & . & . & 1.776 \\
\hline Multimídia & 396 & 191 & . & . & 205 \\
\hline Produção de Multimídia & 2.042 & 119 & . & . & 1.923 \\
\hline Som e Imagem & 168 & 168 & . & . & . \\
\hline Cinema e Vídeo & 2.853 & 687 & 300 & . & 1.866 \\
\hline Total & 15360 & 3911 & 1150 & 45 & 10254 \\
\hline
\end{tabular}

Fonte: INEP - MEC. Dados do Censo da Educação Superior, 2010. Elaboração própria.

$\mathrm{Na}$ relação entre homens e mulheres matriculados nos cursos selecionados, observou-se uma inversão em relação aos anos anteriores, embora ainda foi possível notar certo equilíbrio entre os sexos. Assim, houve em 2010, 7360 mulheres matriculadas, representando 47,9\% dos alunos e 7999 homens, ou $52,1 \%$ do total.

Já em 2016, os dados do Censo da Educação Superior mostraram que o número de cursos voltados para a formação em cinema e audiovisual cresceu 46,5\% em relação a 2010. O número de matriculados, por sua vez, cresceu $60,5 \%$. As instituições privadas foram responsáveis por 70,8\% do total de cursos, e por $67 \%$ do total de matrículas, enquanto as instituições federais permaneceram como as com o maior número de cursos e alunos entre as instituições públicas.

Nesse período, o crescimento das instituições federais foi significativamente menor do que o das instituições privadas. Enquanto as federais cresceram pouco mais de $28 \%$, as privadas cresceram mais que 54\%. Em relação ao número de matrículas, as federais ampliaram em 51\%, ao mesmo tempo em que as privadas aumentaram em 64,4\% o número de matriculados. Em relação à proporção de homens e mulheres, o equilíbrio notado nos anos anteriores permaneceu 
praticamente sem alteração. Foram 11910 mulheres e 11960 homens, ou seja, 49,9\% e 50,1\%, respectivamente.

Tabela 7 - Número de cursos de graduação presenciais relacionados à formação em cinema e audiovisual no Brasil em 2016.

\begin{tabular}{llllll}
\hline Número de Cursos de Graduação Presenciais - 2016 & & & \\
\hline Curso & Total & $\begin{array}{l}\text { Pública } \\
\text { Federal }\end{array}$ & Estadual & Municipal & Privada \\
\hline Animação & 1 & 1 & $\cdot$ & $\cdot$ & $\cdot$ \\
Artes e Mídia & 1 & 1 & $\cdot$ & $\cdot$ & $\cdot$ \\
Artes Gráficas & 1 & 1 & $\cdot$ & $\cdot$ & $\cdot$ \\
Artes Visuais & 42 & 20 & 9 & $\cdot$ & 13 \\
Audiovisuais & 58 & $\cdot$ & 2 & 1 & 55 \\
Cenografia & 6 & 3 & 1 & $\cdot$ & 2 \\
Cinema e Animação & 3 & 2 & $\cdot$ & $\cdot$ & 1 \\
Cinema e Vídeo & 8 & 4 & $\cdot$ & $\cdot$ & 4 \\
Fotografia & 51 & $\cdot$ & $\cdot$ & 1 & 50 \\
Multimídia & 2 & 1 & $\cdot$ & $\cdot$ & 1 \\
Produção de Multimídia & 33 & 5 & $\cdot$ & 1 & 27 \\
Som e Imagem & 27 & 12 & 3 & $\cdot$ & 12 \\
\hline Total & $\mathbf{2 3 3}$ & $\mathbf{5 0}$ & $\mathbf{1 5}$ & $\mathbf{3}$ & $\mathbf{1 6 5}$ \\
\hline
\end{tabular}

Fonte: INEP - MEC. Dados do Censo da Educação Superior, 2016. Elaboração própria. 
Tabela 8 - Número de matriculados nos cursos de graduação presenciais relacionados à formação em cinema e audiovisual no Brasil em 2016.

\begin{tabular}{|c|c|c|c|c|c|}
\hline \multicolumn{6}{|c|}{ Matriculados nos Cursos de Graduação Presenciais - 2016} \\
\hline \multirow{2}{*}{ Cursos } & \multirow{2}{*}{ Total } & \multicolumn{3}{|l|}{ Pública } & \multirow{2}{*}{$\begin{array}{l}\text { Privada } \\
\text { Privada }\end{array}$} \\
\hline & & Federal & Estadual & Municipal & \\
\hline Animação & 43 & 43 & . & . & . \\
\hline Artes e Mídia & 144 & 144 & . & . & . \\
\hline Artes Gráficas & 2 & 2 & . & . & . \\
\hline Artes Visuais & 3.841 & 1.820 & 966 & . & 1.055 \\
\hline Audiovisuais & 6.666 & . & 236 & 194 & 6.236 \\
\hline Cenografia & 309 & 244 & 1 & . & 64 \\
\hline Cinema e Animação & 278 & 231 & . & . & 47 \\
\hline Cinema e Vídeo & 1.231 & 598 & . & . & 633 \\
\hline Fotografia & 4.106 & . & . & 66 & 4.040 \\
\hline Multimídia & 451 & 288 & . & . & 163 \\
\hline Produção de Multimídia & 2.578 & 799 & . & - & 1.779 \\
\hline Som e Imagem & 4.224 & 1.733 & 462 & . & 2.029 \\
\hline Total & 23873 & 5902 & 1665 & 260 & 16046 \\
\hline
\end{tabular}

Fonte: INEP - MEC. Dados do Censo da Educação Superior, 2016. Elaboração própria.

Desse modo, a evolução do número de cursos de graduação em cinema e audiovisual e de matriculados nesses cursos acompanhou, em certa medida, o crescimento geral do ensino superior brasileiro no período destacado. O que se notou foi que, entre 2010 e 2016, mesmo com a desaceleração no crescimento do número de cursos de graduação presenciais em geral, os cursos voltados à formação em cinema e audiovisual mantiveram o ritmo de crescimento, sobretudo nas instituições privadas de ensino. Em relação ao número de matriculados, a intensidade no aumento de matrículas nos cursos de cinema e audiovisual foi ainda maior do que a dos demais cursos.

Em outras palavras, pode-se afirmar que, embora os impactos das crises econômica e política tenham sido sentidos no processo de expansão do ensino superior, não se perceberam seus reflexos, com a mesma intensidade, na formação de profissionais para os campos do cinema e do audiovisual. Em consonância com essa perspectiva, verificou-se também o aumento do número de produções audiovisuais e de filmes de longa-metragem que chegaram aos circuitos comerciais, no 
mesmo período ${ }^{4}$ A partir dos gráficos a seguir, é possível comparar o crescimento dos cursos de cinema e audiovisual com a expansão geral do ensino superior no Brasil no período selecionado.

Gráfico 1 - Expansão dos cursos de ensino superior e dos cursos de graduação presenciais relacionados à formação em cinema e audiovisual no Brasil em anos selecionados entre 2000 e 2016.

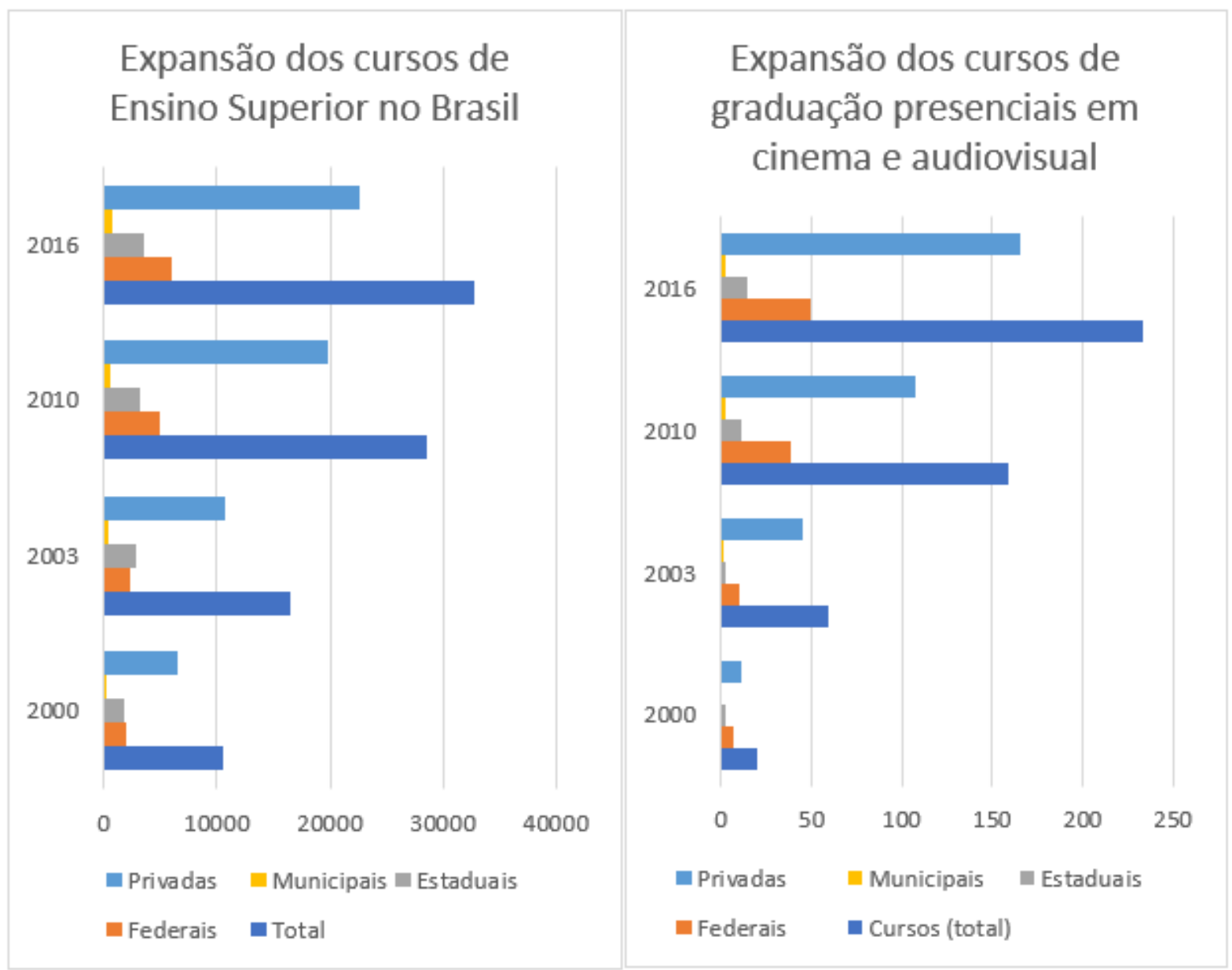

Fonte: INEP - MEC. Dados do Censo da Educação Superior, 2000, 2003, 2010 e 2016. Elaboração própria.

\footnotetext{
${ }^{4}$ Segundo dados da Ancine, de 2009 a 2016, o crescimento no número de longas metragens lançados comercialmente foi da ordem de 70\% (ANCINE, 2017).
} 
Gráfico 2 - Expansão das matrículas nos cursos de ensino superior e nos cursos de graduação presenciais relacionados à formação em cinema e audiovisual no Brasil em anos selecionados entre 2000 e 2016.

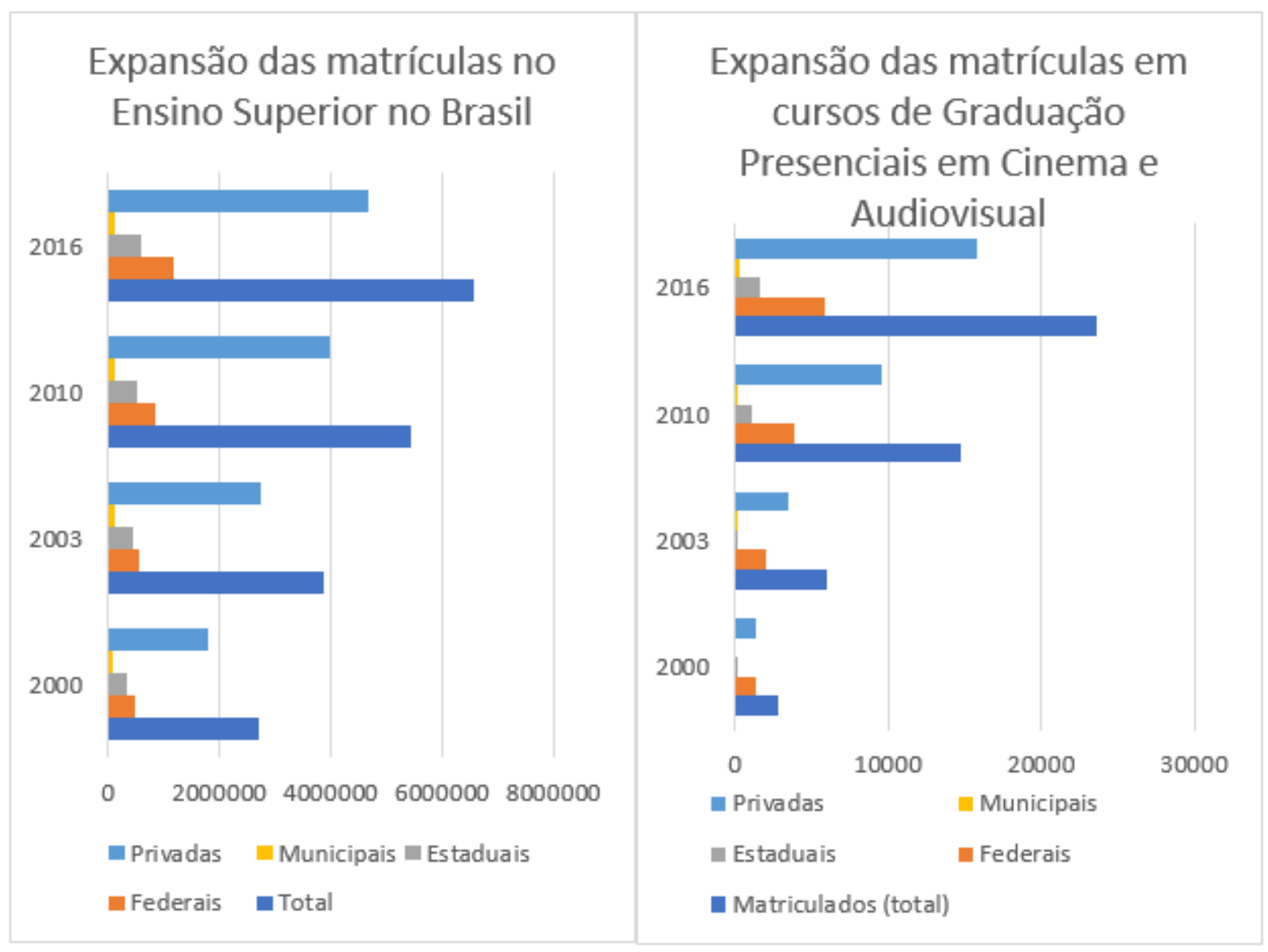

Fonte: INEP - MEC. Dados do Censo da Educação Superior, 2000, 2003, 2010 e 2016. Elaboração própria.

O significativo crescimento, na última década, do número de cursos de graduação em cinema e audiovisual nas universidades públicas, em especial nas federais, se beneficiou, em larga medida, dos projetos de ampliação e democratização do ensino superior no Brasil, como o Reuni, nos governos Lula e Dilma. No entanto, esses projetos esbarraram em limites orçamentários significativos. Em outras palavras, o projeto de ampliação das universidades públicas federais não foi acompanhado pelo incremento financeiro adequado a esta ampliação. Dessa forma, a criação de novos cursos, novas vagas e novas universidades federais, em muitos casos, significou "dividir a miséria".

O que uma análise mais cuidadosa do período nos revelou foi que, na verdade, o que Santos (2016) chama de neodesenvolvimentismo lulista, ao mesmo tempo em que buscava se contrapor ao período de estagnação das décadas anteriores e de associá-lo às políticas neoliberais, nada mais fez do que reforçar uma política macroeconômica conservadora. De acordo com esse autor: 


\begin{abstract}
Debaixo do verniz retórico, remetendo a um ideário que outrora pretendeu conciliar capitalismo e nação na periferia, o que se observa na prática é uma política econômica conservadora, que aceita os parâmetros macroeconômicos e o horizonte histórico afirmados pelo neoliberalismo. [...] Assim, a retórica neodesenvolvimentista cumpre um papel ideológico regressivo ao estreitar o debate econômico, restrito à microeconomia, e encurtar o horizonte da discussão política, limitado à conjuntura. Ao reduzir o horizonte da mudança social aos parâmetros aceitos pelo próprio neoliberalismo, a política é encolhida a uma discussão sobre o ritmo e a intensidade do arrocho neoliberal, distinguindo-se somente em aspectos acessórios [...] (SANTOS, 2016, p. 57).
\end{abstract}

Embora, tão logo tenha assumido o governo federal, a gestão petista tenha apontado para uma inflexão das políticas de ensino superior no sentido diferente daquele adotado nos governos anteriores, é importante ressaltar que o mesmo decreto de 2003 (BRASIL, 2003b), que instituiu o Grupo de Trabalho Interministerial para a reestruturação das instituições federais de ensino, também estabeleceu parâmetros limitados para esse processo de reestruturação.

\title{
Considerações finais
}

Ao se observar a ampliação do ensino superior em cinema e audiovisual, em série histórica, alguns elementos se tornam contundentes. Embora a dinâmica de crescimento dos cursos voltados para a formação profissional em cinema e audiovisual tenha uma lógica própria, atendendo a uma demanda específica do setor, em linhas gerais, ela acompanha um movimento mais amplo que caracteriza a política de expansão do ensino superior de forma geral. Como os dados apresentados informam, o crescimento das Universidade Federais é bastante relevante no período, mas a prevalência das Instituições Privadas de Ensino é fundamental para se compreender a lógica por trás destas políticas de expansão. Em outras palavras, incapaz de reverter a lógica da agenda neoliberal, a reestruturação do ensino superior oferecido pelas instituições federais busca se adequar aos contornos da eficiência na gestão, exemplificada na redução do custo por aluno, na flexibilização de currículos e no aumento do número de alunos por professor, reduzindo a política de expansão do ensino superior à lógica da racionalização de recursos (SANTOS; CERQUEIRA, 2009). Vale destacar que a participação do setor privado no número de cursos e de matriculados permaneceu quase inalterada, entre 2005 e 2010, ao passo que as instituições estaduais e municipais perderam espaço e contribuíram muito pouco com a expansão do ensino superior. Assim, o espaço conquistado pelas instituições federais no ensino superior não se deu em detrimento do setor privado. Ao contrário, este se beneficiou das políticas de ampliação do acesso, como o FIES e o Prouni.

A questão em torno da relação e do hiato existentes entre o ensino de cinema e audiovisual e o mercado faz parte também do debate acerca da profissionalização do cinema no Brasil e do 
pensamento industrial cinematográfico brasileiro. Embora, nos últimos anos, inúmeros agentes tenham assumido a proposição de industrializar o cinema nacional e torná-lo economicamente viável e sustentável, capaz de concorrer em pé de igualdade com o produto estadunidense, é notável também a falta de esforços efetivos no sentido da consolidação da cadeia produtiva do cinema como um todo e na formação e qualificação de profissionais que atuarão no segmento. Tudo isso somado a uma absoluta desregulamentação das relações de trabalho, característica marcante das profissões artísticas de forma geral e do cinema em especial.

\section{Referências}

ANCINE. Listagem de filmes brasileiros lançados: 1995 - 2016. Observatório Brasileiro do Cinema e do Audiovisual, [S.1.], 2017.

BRASIL. Ministério da Educação. Sinopse Estatística Censo da Educação Superior. Brasília: Ministério da Educação, 1995.

BRASIL. Sinopse Estatística Censo da Educação Superior. Brasília: Ministério da Educação, 2000.

BRASIL. Sinopse Estatística Censo da Educação Superior. Brasília: Ministério da Educação, 2003a.

BRASIL. Decreto Presidencial de 20 de outubro de 2003. Institui o Grupo de Trabalho Interministerial encarregado de analisar a situação atual e apresentar plano de ação visando a reestruturação, desenvolvimento e democratização das Instituições Federais de Educação Superior - IFES. Brasília-DF: 21 out. 2003b.Disponível em:

http://www2.camara.leg.br/legin/fed/decret_sn/2003/decreto-52428-20-outubro-2003-603937norma-pe.html. Acesso em: 25 de jan. 2018.

BRASIL. Sinopse Estatística Censo da Educação Superior. Brasília: Ministério da Educação, 2010.

BRASIL. Sinopse Estatística Censo da Educação Superior. Brasília: Ministério da Educação, 2016.

BULLONI, M. N. O trabalho em redes de projetos e seus processos de regulamentação. Um estudo num segmento da produção audiovisual argentina. In: SEGNINI, L. R. P.; BULLONI, M. N. Trabalho artístico e técnico na indústria cultural. São Paulo: Itaú Cultural, 2016.

DOURADO, L. F. Reforma do Estado e as políticas para a educação superior no Brasil nos anos 90. Educação e Sociedade, Campinas, 23, n. 80, p.235-253 set. 2002.

MARQUES, A.; AMÂNCIO, T. Entrevista com Nelson Pereira dos Santos. Cadernos do Forcine, v. 1, p.15-23, 2014.

MOURÃO, M. D. Breve histórico de área do ensino de cinema e do audiovisual. Cadernos do Forcine, [s.l.], v. 1, 2014. 
RIBEIRO, D. C. L. et al. Mercado Audiovisual e formação profissional: o perfil dos cursos superiores em cinema e audiovisual no Brasil. Cadernos do Forcine, São Paulo, v. 3, p. 76-112, jan.set. , 2017.

RODRIGUES, L. Proposta de história. Cadernos do Forcine, [s.1.], p. 33-55, 2014.

SANTOS, A. P. D.; CERQUEIRA, E. A. D. Ensino Superior: trajetória histórica e políticas recentes. In: IX COLÓQUIO INTERNACIONAL SOBRE GESTÃO UNIVERSITÁRIA NA AMÉRICA DO SUL. [s.n.], 2009, Florianópolis. Anais eletrônicos. Florianópolis-SC: UFSC, 2009. Disponível em:

https://repositorio.ufsc.br/xmlui/bitstream/handle/123456789/35836/Ensino\%20Superior\%2 0trajetoria $\% 20$ historica $\% 20 \mathrm{e} \% 20$ politicas $\% 20$ recentes.pdf?sequence $=1 \&$ \&is Allowed $=$ y. Acesso em: 23 jun. 2021.

SANTOS, F. L. B. D. Além do PT: a crise da esquerda brasileira em perspectiva latino-americana. São Paulo: Elefante, 2016 